\title{
Piyasada Satılan Ticari Propolis Örneklerinin Biyoaktif Bileşenlerinin Belirlenmesi
}

\author{
Osman Sağdıç ${ }^{1}$, Salih Karasu²*, Hamza Göktaş ${ }^{3}$ \\ ${ }^{1}$ Yıldız Teknik Üniversitesi, Kimya Metalurji Fakültesi, Gıda Mühendisliği Bölümü, İstanbul, Türkiye (ORCID: 0000-0002-2063-1462) \\ ${ }^{2}$ Yıldız Teknik Üniversitesi, Kimya Metalurji Fakültesi, Gıda Mühendisliği Bölümü, İstanbul, Türkiye (ORCID: 0000-0002-0421-6103) \\ ${ }^{3}$ Yıldız Teknik Üniversitesi, Kimya Metalurji Fakültesi, Gıda Mühendisliği Bölümü, İstanbul, Türkiye (ORCID: 0000-0001-9802-9378)
}

(İlk Geliş Tarihi 16 Mart 2020 ve Kabul Tarihi 23 Mayıs 2020)

(DOI: 10.31590/ejosat.734204)

ATIF/REFERENCE: Sağdıç, O., Karasu, S. \& Göktaş, H. (2020). Piyasada Satılan Ticari Propolis Örneklerinin Biyoaktif Bileşenlerinin Belirlenmesi. Avrupa Bilim ve Teknoloji Dergisi, (19), 19-31.

$\ddot{O} \mathbf{z}$

Tüketicilerin gıda ve içerikleri hakkında daha bilinçli hale gelmesi, sağlık faydası olan fonksiyonel gıdaları tercih etmeleri nedeniyle gıda ürünlerinin biyoaktif bileşenlerinin incelenmesi önemli hale gelmiştir. Yapılan bilimsel çalışmalarla içerdiği biyoaktif maddeler nedeniyle birçok sağlık faydası tespit edilen propolis, tüketiciler tarafından takviye edici gıda olarak tercih edilen ürünler arasında ilk sıralarda yer almaktadır. Ancak ülkemizde Helal gıda kapsamında alkol kullanılmadan farklı çözgen ekstraksiyonlarıyla üretilmiş propolisin yaygın olması ve bunun yanında alkol ekstraksiyonu ile üretilmiş propolisin bulunması, marketlerde satılan propolisin biyoaktif özelliğinin çeşitlilik göstermesine neden olmaktadır. Bu durum standardizasyonu da engellemektedir. Bu çalışmanın amacı; ülkemizde marketlerde satılan ticari propolis örneklerinin biyoaktif bileşenlerinin belirlenmesi ve sonuçların karşılaştırmalı olarak ortaya konulmasıdır. Bu kapsamda, yerli ve yabancı markalardan toplam 14 farklı ticari propolis örneği temin edilmiştir. Farklı çözücü maddeler (alkol, su, propilen glikol vb.) içeren, damlalıklı şişe ve tek kullanımlık saşe ambalajdaki bu propolis örneklerinde toplam fenolik ve toplam flavonoid madde miktarı ile fenolik bileşen kompozisyonu analizi yapılmıştır. Toplam fenolik madde miktarı spektrofotometrik yöntemle, fenolik bileşen kompozisyonu ve toplam flavonoid madde miktarı ise kromatografik metotla LCMS-MS cihazında tespit edilmiştir. Toplam 43 farklı fenolik madde taraması yapılmıştır. Ürünlerin etiket üstünde beyan edilen propolis oranları farklı olduğu için toplam fenolik ve flavonoid madde miktarları her birinde $\% 50$ propolis içermesi durumuna göre hesaplanmış ve karşılaştırma yapılmıştır. En yüksek toplam fenolik ve toplam flavonoid madde miktarı su bazlı olarak beyan edilen tek kullanımlık saşe üründe tespit edilmiştir. Yine su bazlı olarak beyan edilen tek kullanımlık saşe üründe, analiz edilen 43 farklı fenolik bileşenden, 42 tanesi tespit edilerek fenolik madde çeşitliliği bakımından da en üst sırada yer almıştır. Öte yandan iki farklı su bazlı propolis örneklerinde flavonoid madde tespit edilememiştir. Tespit edilen bu farklılıkların, kullanılan çözücünün yanı sıra bu çözücüye uygun ekstraksiyon metodunun kullanılması ve kullanılan hammaddenin niteliği ile ilgili olduğu düşünülmektedir. Bu nedenle raftaki propolis ürünlerinin tercihi sırasında örneğin içerdiği propolis oranı ve çözücü maddenin yanısıra biyoaktif madde içeriğinin de biliniyor olması gerekmektedir. Bu anlamda, tüketicilerin satın alacakları ürünlerin içerdiği biyoaktif madde miktarı bilgisine ulaşabilmesi önem taşımaktadır.

Anahtar Kelimeler: Propolis ürünleri, biyoaktif bileşen, fenolikler, flavonoid madde

\section{Determination of Bioactive Components of Commercial Propolis Samples Sold in the Market}

\begin{abstract}
Consumers has become more conscious about their food and ingredients and they began to prefer foods that have health benefits. Hence, examination of bioactive compounds of food products has become important. Propolis, which is a bee product known to have many health benefits due to the bioactive substances it contains, has become a very popular food supplement. However, in our
\end{abstract}

\footnotetext{
* Yıldız Teknik Üniversitesi, Kimya Metalurji Fakültesi, Gıda Mühendisliği Bölümü, İstanbul, Türkiye, ORCID: 0000-0002-0421-6103, skarasu@yildiz.edu.tr
} 
country, propolis produced with different solvent extractions without the use of alcohol within the scope of Halal food, as well as the presence of propolis produced with alcohol extraction cause the bioactive feature of propolis sold in the markets to vary. This situation also prevents standardization. In this study; it is aimed to determine the bioactive components of commercial propolis samples and show the results comparatively. A total of 14 different commercial propolis products were obtained from domestic and foreign brands. They contained different solvents (such as alcohol, water, propylene glycol) and were packaged in dropper bottles and disposable sachets. Total phenolic content, total flavonoid content and phenolic profile analysis were performed for each sample. Total phenolic content was determined by spectrophotometric method, phenolic profile and total amount of flavonoid substance were determined by chromatographic method at LC-MS-MS. A total of 43 different phenolic substance were analysed. Since the propolis content of the products declared on the labels were different, the total phenolic content and the total flavonoid content were calculated based on the fact that they contained $50 \%$ propolis. It was found that, the water based propolis product in the disposable sachet had the highest amount of the total phenolic and total flavonoid content. At the same time, 42 of the 43 phenolic components analyzed, were detected at this product hence it was ranked at the top in terms of the variety of phenolic components. On the other hand, any flavonoid component could be detected in the other two water based propolis products. These differences could be related to the extraction solvent and method and/or the quality of the raw material. For this reason, consumers need to know the propolis content and the solvent type in the product as well as the amount of bioactive components. At this point, it becomes important for the consumers to be able to access the information about the amount of the bioactive components of product they will buy.

Keywords: Propolis products, bioactive compounds, phenolics, flavonoids.

\section{Giriş}

Propolis; işçi arıların otsu ve odunsu bitkilerin kabuk, dal, filiz, tomurcuk, salgı maddeleri gibi çeşitli kısımlarından topladıkları reçine içeren bileşenleri, salgıladıkları enzimlerle muamele ederek biraz bal mumu ilavesiyle oluşturdukları bir arı ürünüdür (Duman, 2010).

Son yıllarda, tüketiciler gıda ve içerikleri hakkında daha bilinçli hale gelmiştir. Sağlık faydaları nedeniyle doğal ve besleyici gıdaların kullanımına büyük ilgi duyulmaktadır (Belščak ve ark., 2009). Bu nedenle, gıda ürünlerinin biyoaktif bileşenlerini incelemek çok önemli hale gelmiştir.

Propolis, antimikrobiyal, antioksidan, antienflamatuar, immünomodülatör, antitümör, antikanser, antiülser, hepatoprotektif, kardiyoprotektif ve nöroprotektif aktivite gibi geniş bir biyolojik ve farmakolojik özelliklere sahip bir arı ürünüdür. Propolisin bu sağlık özellikleri içerdiği polifenoller, fenolik aldehitler, seskiterpen -kinonlar, kumarinler, amino asitler, steroidler ve inorganik bileşikler gibi bileşenlere bağlanmaktadır (Farooqui \& A. Farooqui, 2012).

Propolis, 300'den fazla bileşik içeren kompleks bir kimyasal yapıya sahiptir (Ahangari ve ark., 2018). Temel olarak reçine ( \% $\%$ ), balmumu $(\sim \% 30)$, esansiyel ve aromatik yağlar $(\sim \% 10)$, polen $(\sim \% 5)$ ve amino asit, mineral, şeker, terpenler, fenolik maddeler gibi farklı bileşenler ( \%5) içermektedir (Burdock, 1998; Toreti ve ark., 2013; Huang ve ark., 2014; Bogdanov, 2017; Ahangari ve ark., 2018; Anjum ve ark., 2019). Flavonoidler, fenolik asitler, tanenler, stilbenler, kurkuminoidler, kumarinler ve kininler propolisin biyolojik etkilerine katkıda bulunan fenolik bileşiklerdir. Propoliste bulunan flavonoidler; flavonlar, flavonoller, flavanonlar, flavanonoller, kalkononlar, dihidro-kalkonlar, izoflavonlar, izodihidroflavonlar, flavanlar, izoflavanlar ve neoflavonoidler olarak sınıflandırılmaktadır. Terpenoidler ise; propolisin karakteristik reçine kokusundan sorumlu olan ve propolisin farmakolojik etkilerine katkıda bulunan uçucu maddelerdir (Uzel ve ark., 2005; Toreti ve ark., 2013; Huang ve ark., 2014; Ahangari ve ark., 2018).

Propolisin bileşimi temel olarak elde edildiği botanik kaynağa bağlıdır. Propolisin elde edildiği bitkisel kaynaklar şu şekilde siralanabilir: Pinus nigra, Populus spp., Xanthorrhoea spp., Araucaria spp., Baccharis spp., Pinus italica, Clusia spp., Delchampia spp., Betula spp., Acer spp., Aesculus hippocastanum, Acacia spp, Alnus spp., Ambrossia deltoidea, Cistus spp., Plumeria acuminata, Plumeria acutifolia, Plumeria euramericana, Clusia minör (Burdock, 1998; Anonim, 2020). Öte yandan, propolisin toplandı̆̆ı iklim, sezon ve bölge de propolisin kimyasal yapısına etki eden diğer parametrelerdir (Uzel ve ark., 2005). Örneğin; tropikal bölgelerdeki propolislerde lignanlar oldukça baskın iken; Avrupa, Asya ve Amerika'da caffeic acid fenetil ester (CAPE) baskın şekilde görülmektedir. 3,5-diprenil-4-hidroksisinnamik asit ve artepilin $\mathrm{C}$ ise Brezilya yeşil propolisinin karakteristik bileşenleridir (Cornara ve ark., 2017).

Propolis kovandan alındığı haliyle tüketilemez. İlk aşamada propolisin ham halinde bulunan balmumu ve yabancı maddelerin uzaklaştırılması ve daha sonra ekstraksiyon işlemi yapılması gerekmektedir (Galeotti ve ark., 2018). Bu aşamada, kullanılan ekstraksiyon yöntemi büyük bir önem taşımaktadır çünkü son ürünün biyoaktif bileşenlerinin miktarı ve kalitesi uygulanan ekstraksiyon metodundan doğrudan etkilenmektedir. Propolisin ekstraksiyonunda genel olarak maserasyon yöntemi kullanılmakta olup çözücü olarak ise \%70’lik etanol çözeltisi kullanılmaktadır. Son zamanlarda, ultrasonik destekli ekstraksiyon, mikrodalga destekli ekstraksiyon, süperkritik ekstraksiyon gibi daha etkili ekstraksiyon yöntemleri geliştirilmiştir (Trusheva ve ark., 2007; Devequi-Nunes ve ark., 2018). Öte yandan, alkolün yarattığı olumsuz sonuçlar (son üründe yarattığı duyusal problemler, kozmetik ve farmasötik ürünlerde kullanımının kısıtlı olması, çocuklarda ve hamilelerde kullanılamaması) alkolsüz ekstraksiyon yöntemlerinin geliştirilmesine yol açmıştır (Kubiliene ve ark., 2015; Petkov ve ark., 2018; Bakkaloğlu \& Arıcı, 2019). Bu nedenle, piyasada çözücü olarak etil alkol veya son üründe taşıyıcı olarak su, mono propilen glikol, gliserin, zeytinyağı, polietilen glikol içeren farklı propolis ürünleri görülmeye başlanmıştır. Fakat ekstraksiyonda ve/veya taşıyıcı olarak kullanılan mono propilen glikol gibi alkol türevi maddelerin de yetişkin ve çocuklarda merkezi sinir sistemi, böbrek, karaciğer, solunum ve kalp fonksiyonları üzerinde olumsuz 
etkileri olduğuna dair çalışmalar bulunmaktadır (Martin \& Finberg, 1970; Arulanantham \& Genel, 1978; Cate \& Hedrick, 1980; Glascow ve ark., 1983; O’Donnell ve ark., 2000; Zar ve ark., 2007; Lim ve ark., 2014). Öte yandan propolisteki bioaktif bileşenlerin konvansiyonel ekstraksiyon metotları kullanıldığında yağda ve suda çözünürlüğünün çok düşük olduğu bilinmektedir (Kubiliene ve ark., 2015). Ancak son yıllarda suyun çözücü özelliği geliştirilerek uygulanan yeni ekstraksiyon metotları ile su ile ekstrakte edilen ve son üründe alkol ve türevleri içermeyen, propolis ve sudan oluşan propolis ürünleri elde edilmektedir.

Piyasada farklı çözücü/taşıyıcı içeren, farklı üretim teknolojisi ve ambalaj tipleri ile üretilen farklı formatlarda (tek kullanımlık, damlalıklı, sprey vs) propolis ürünleri bulunmaktadır. Bu kadar farklı çeşitte ürün bulunması, tüketicilerin aklında hangilerinin daha etkili olduğuna dair sorular ortaya çıkarmaktadır. Daha önce yapılan çalışmalara bakıldığında ticari ürünleri bu anlamda inceleyen çok fazla çalışma bulunmadığı ayrıca yapılan çalışmalarda bakılan fenolik madde sayısının çok kısıtlı olduğu görülmüştür. Tüm bu nedenlerden dolayı bu çalışmada; yurt içi ve yurt dışından temin edilen farklı markalardaki ticari propolis ürünlerinin biyoaktif bileşenlerinin tespit edilmesi amaçlanmıştır. Bu doğrultuda ürünlerin toplam fenolik ve toplam flavonoid madde miktarlarının tespit edilmesi, 43 farklı fenolik madde analizi yapılarak fenolik bileşen kompozisyonlarının ortaya konulması ve sonuçların karşılaştırmalı olarak incelenmesi hedeflenmektedir.

\section{Materyal ve Metot}

\subsection{Propolis Örnekleri}

Bu çalışmada, Kore (1 adet), Brezilya ( 2 adet) ve Türkiye ( 9 adet) olmak üzere 3 ülkeden toplam 14 adet propolis ekstraktı raflardan satın alınarak incelenmiştir. Ürünlerin etiketlerinde beyan edilen bilgiler ve ambalaj şekilleri Tablo 1'de verilmiştr.

Tablo 1. Çallşmada Kullanılan Ticari Propolis Örneklerinin Kodları ve Özellikleri (Table 1. Code Number and Chracteristic of Propolis Samples)

\begin{tabular}{|c|c|c|}
\hline Ürün & Etiket Beyanı & Ambalaj Şekli \\
\hline P1 & Su bazlı propolis ekstresi (Alkol içermediği beyan edilmiștir.) & Damlalıklı şişe \\
\hline P2 & Propolis sıvı ekstraktı (farmasötik gliserin ve su içerdiği beyan edilmiştir.) & Damlalıklı şişe \\
\hline P3 & Alkolsüz suda çözünür propolis & Damlalıklı şişe \\
\hline P4 & Alkolde ekstrakte edilmiş yeşil propolis & Damlalıklı şişe \\
\hline P5 & Su bazlı propolis & Damlalıklı şişe \\
\hline P6 & Organik su bazlı propolis & Damlalıklı şişe \\
\hline P7 & Propolis sıvı ekstraktı (Propolisin suda çözündürülmesiyle elde edildiği beyan edilmiştir.) & Damlalıklı şişe \\
\hline P8 & Su bazlı propolis & Damlalıklı şişe \\
\hline P9 & Organik su bazlı propolis & Damlalıklı şişe \\
\hline P10 & Suda çözünebilir propolis (Propolisin su ve glikol çözeltisi ile ekstrakte edildiği beyan edilmiştir.) & Damlalıklı şişe \\
\hline P11 & Propolis damla (Propolisin su ve etanol çözeltisi ile ekstrakte edildiği beyan edilmiştir.) & Damlalıklı şişe \\
\hline P12 & $\begin{array}{l}\text { Propolis damla (Propolisin su ve etanol çözeltisi ile ekstrakte edildiği beyan edilmiştir.) } \\
\end{array}$ & Damlalıklı şişe \\
\hline P13 & $\begin{array}{l}\text { Su bazlı propolis (Propolisin, Ar-Ge çalışması sonucu geliştirilen metod kullanılarak, su ile } \\
\text { ekstrakte edildiği beyan edilmiştir) }\end{array}$ & Tek kullanımlık saşe \\
\hline P14 & $\begin{array}{l}\text { Su bazlı propolis (Propolisin, Ar-Ge çalışması sonucu geliştirilen metod kullanılarak, su ile } \\
\text { ekstrakte edildiği beyan edilmiştir.) }\end{array}$ & Tek kullanımlık saşe \\
\hline
\end{tabular}

\subsection{Kimyasallar}

Ultra saf su, Sodyum karbonat (Merck 106392), Folin Ciocalteu Reaktifi (FCR) (Merck 109001), Etil alkol (Merck 100983), Formik asit (Sigma Aldrich 251364), Gallic asit (Sigma Aldrich 147915), Homogentisic asit (Sigma Aldrich 168688), Protocatechuic asit (Sigma Aldrich 37580), (+)-Catechin Hydrate (Sigma Aldrich C1251), 4-OH Benzoic asit (Sigma Aldrich 242381), Gentisic asit (Sigma Aldrich 149357), Chlorogenic asit (Sigma Aldrich C3878), Vanilic asit (Sigma Aldrich H36001), Caffeic asit (Sigma Aldrich C0625), (-) Epi-Catechin (Sigma Aldrich 855235), P-Coumaric asit (Sigma Aldrich C9008), (+/-)Taxifolin Hydrate (Sigma Aldrich T4512), Trans-Ferrulic asit (Sigma Aldrich 128708), 3,4-Dimethoxy Benzaldehyde (Sigma Aldrich 143758), M-Coumaric asit (Sigma Aldrich 92649), 2-OH Cinnamic asit (Sigma Aldrich H22809), Resveratrol (Sigma Aldrich R5010), 3,4-Dimethoxy Cinnamic asit (Sigma Aldrich D133809), Cinnamic asit (Sigma Aldrich 133760), (+/-) Naringenin (Sigma Aldrich N5893), Quercetin (Sigma Aldrich Q4951 ), Hespercetin (Sigma Aldrich W431300) Genistein (Sigma Aldrich G6649), Kaempferol (Sigma Aldrich 60010 ), Apigenin (Sigma Aldrich 10798 ), Pinocembrin (Sigma Aldrich P5239) Chrysin (Sigma Aldrich C80105 ), Myricetin (Sigma Aldrich 70050 ), Galangin (Sigma Aldrich 48291), Syringic asit (Sigma Aldrich S6881), Rutin Hydrate (Sigma Aldrich R5143 ), CAPE Caffeic acid phenethyl ester (Sigma Aldrich C8221), Isorhamnetin (Sigma Aldrich 17794), Luteolin (Sigma Aldrich L9283), Pinobanksin (Sigma Aldrich 68530), Rosmarinic acid (Sigma Aldrich R4033), Ellagic acid (Sigma Aldrich E5220), Methyl Syringat (Sigma Aldrich S409448), Epi-Gallo-Catechin (Sigma Aldrich 08108), Phenyllactic asit (Alfa Aeser L09854), Phloroglucinol (Sigma Aldrich 79330), Shikimic asit (Alfa Aeser L04848), Syringic asit (Sigma Aldrich S6881), Trans-Cinnamaldehyde Sigma Aldrich C80687), Metanol (J.T. Baker 8402), Etil Asetat (Merck 100868), NaCl (Merck 106404). 


\subsection{Toplam Fenolik Madde Miktarının Belirlenmesi}

Propolis numunelerinde spektrofotometrik yöntemle toplam fenolik madde miktarı belirlenmiştir (Popova ve ark., 2007; Bayram ve ark., 2019; Aybastıer, 2020). Etanol, glikol veya su fazındaki sıvı propolis ekstraktları tahmini konsantrasyon değerine seyreltme yapılarak analiz edilmiştir. Genelde başlangıç için 1:100 veya 1:50 oranında kendi fazındaki çözeltisi ile seyreltmeler yapılmıştır. Eğer seyreltme sonrası elde edilen çözelti bulanık ise $0,45 \mu \mathrm{m}$ lik filtreden geçirildikten sonra analize alınmıştır.

Propoliste toplam fenolik maddelerin ölçümü için $25 \mu \mathrm{L}$ çözelti alınmış ve üzerine Folin Ciocalteu çözeltisi (konsantre haliyle kullanılmıştır) ve sodyum karbonat çözeltisi (\%20, w/v) ve ultra saf su eklenerek 1 saat karanlıkta oda sicaklığında inkübasyona bırakılmıştır. Kalibrasyon grafiği için farklı konsantrasyonlarda (Blank, 200, 400, 800, 1600 ve 2000 mg GAE/L) gallic acid çözeltileri kullanılmıştır. Bir saat sonunda sonuçlar spektrofotometrede $760 \mathrm{~nm}$ 'de kalibrasyon eğrisine karşı mg GAE/L olarak okunmuştur (GAE=Galik Asit Eşdeğeri). Sonuçlar aşağıdaki gibi seyreltme miktarına göre konsantrasyon değeri mg GAE/L cinsinden raporlanmıştır:

Numunedeki TPC $(m g G A E / L)=$ konsantrasyon $(m g G A E / L) \times$ seyreltme miktarl

\subsection{Toplam Flavonoid Madde Miktarının Belirlenmesi}

Kromotografik yöntemle fenolik bileşenlerin kompozisyonu tek tek belirlendikten sonra tespit edilen flavonoid maddelerin (apigenin, chrisin, galangin, genistein, hesperetin, 1sorhamnetin, kaempferol, luteolin, myristin, naringenin, pinobanksin, pinocembrin, quercetin, rutin, taxifolin) miktarları toplanarak toplam flavonoid madde miktarı belirlenmiştir.

\subsection{Propolis Örneklerinin Fenolik Bileşiklerin Belirlenmesi}

Propolis numunelerinin fenolik bileşenlerinin kompozisyonu kromotografik yöntemle belirlenmiştir (Escriche \& Juan-Borrás, 2018). Propolis örneklerinden tahmini konsantrasyon değerine göre belirli bir hacimde veya kütlede örnek alınmıştır. LC-MS-MS için genellikle ilk seyreltme 1:1000 olacak şekilde ayarlanmıştır. Elde edilen sonuçlara göre seyreltme miktarı azaltılarak veya arttırılarak analiz tekrar edilmiştir. Bunun için numunelerden $100 \mu \mathrm{L}$ veya numune yoğun bir sıvı ise $0,100 \mathrm{~g}$ tartılarak alınmıştır. Üzerine $10 \mathrm{~mL}$ çözücü eklenip, ultrasonik banyoda çözülmüştür. Çözülen örnek $0,45 \mu \mathrm{m}$ şırınga ucu filtre ile filtrelenmiştir. Filtre edilen örnekten $100 \mu \mathrm{L}$ bir viale alınmış, $400 \mu \mathrm{L}$ metanol ve $500 \mu \mathrm{L}$ USS eklenmiş ve LC-MS/MS cihazına verilmiştir.

Tüm standartlardan $2000 \mathrm{mg} / \mathrm{L}$ olacak şekilde metanolde stok standart hazırlanmıştır. Propolislerdeki fenolik bileşen seviyelerine göre, her bir fenolik bileşen için 50-1000 $\mathrm{g} / \mathrm{L}$ aralığında standart serilerini içeren standart karışımları hazırlanmıştır. Standartlara ait LS-MS-MS kromatogramları Şekil 1'de verilmiştir.

Propoliste fenolik bileşen kompozisyonu Waters marka, Xevo TQD MS model LC-MS-MS cihazında yapılmıştır. CORTECS T3 Waters (1,6 um 2,1 x $150 \mathrm{~mm}$ ) kolon ile $30^{\circ} \mathrm{C}$ kolon sıcaklığında, \%0,01 Asetik asit içeren ultra saf su (Mobil Faz A) ve 80:20 Asetonitril:Metanol (Mobil faz B) mobil fazları ile 0,25 $\mu \mathrm{L} / \mathrm{dk}$ akış hızında enjeksiyon yapılmıştır. Gradient, \%98 mobil faz A, \%2 mobil faz B ile başlayıp, 35. dakikada \%45 mobil faz A, \%55 mobil faz B'ye geçilmiştir, 37. dakikaya kadar \%5 mobil faz A, \%95 mobil faz B olarak devam edilmiştir. Hemen sonrasında mobil fazlar başlangıç durumuna alınarak, 40. dakikada gradient sonlandırılmıştır. MS parametreleri şu şekildedir; kapileri voltaj 2kV, desolvasyon sıcaklığ $450{ }^{\circ} \mathrm{C}$, desolvasyon akışı $850 \mathrm{~L} / \mathrm{Sa}$, Kone gaz akışı $50 \mathrm{~L} / \mathrm{sa}$, collision gaz akış1 $0,17 \mathrm{~mL} / \mathrm{dk}$. 
GD

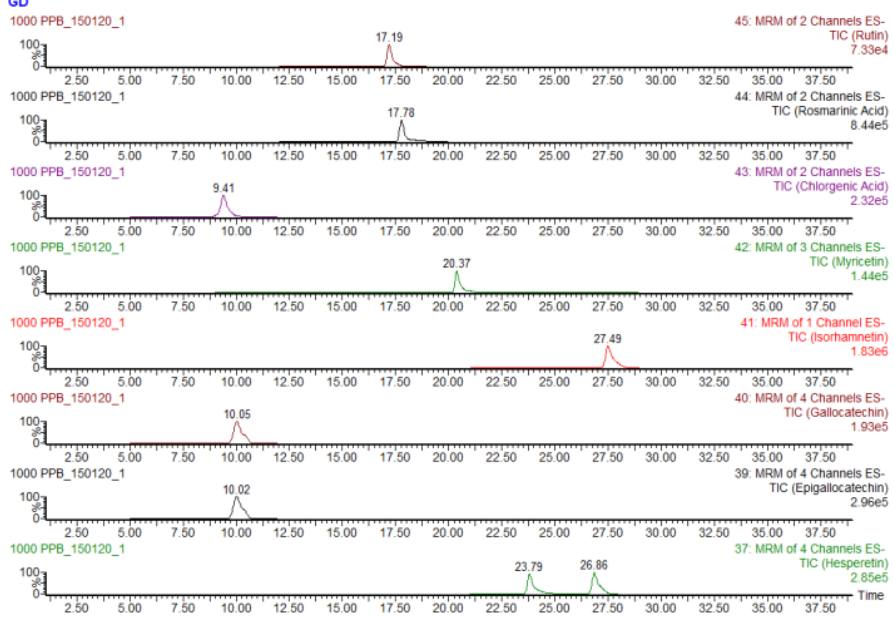

a)

${ }_{1000}^{G P P_{1}-150120-1}$

${ }^{100} 3$

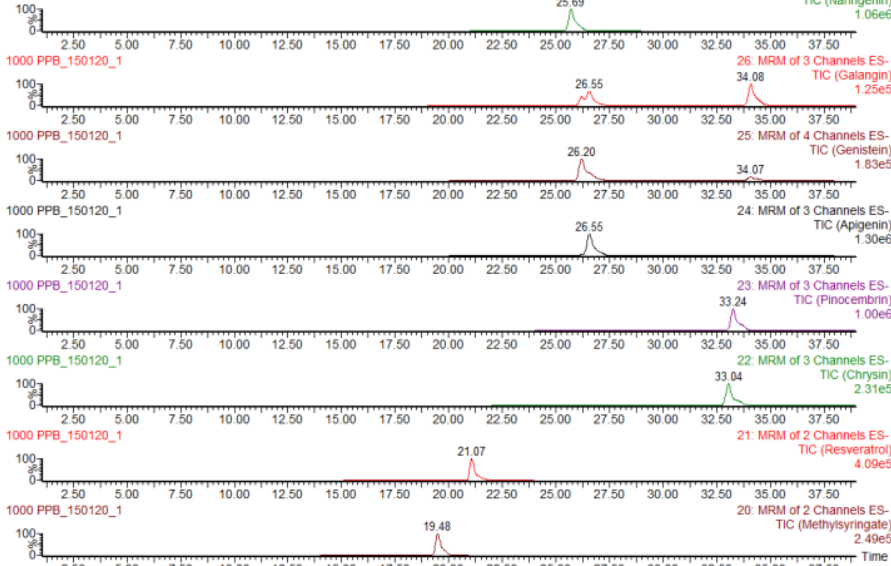

c)

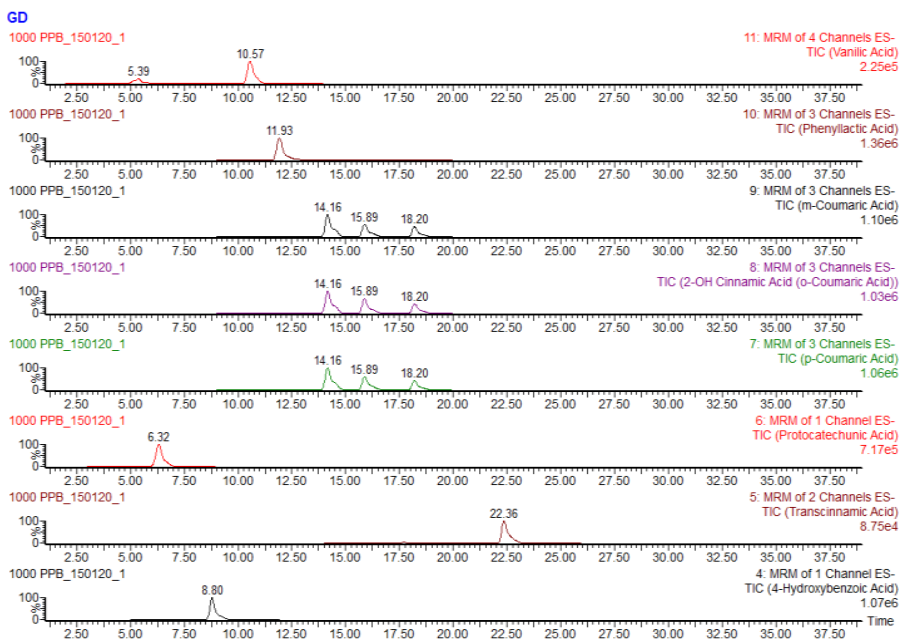

GD

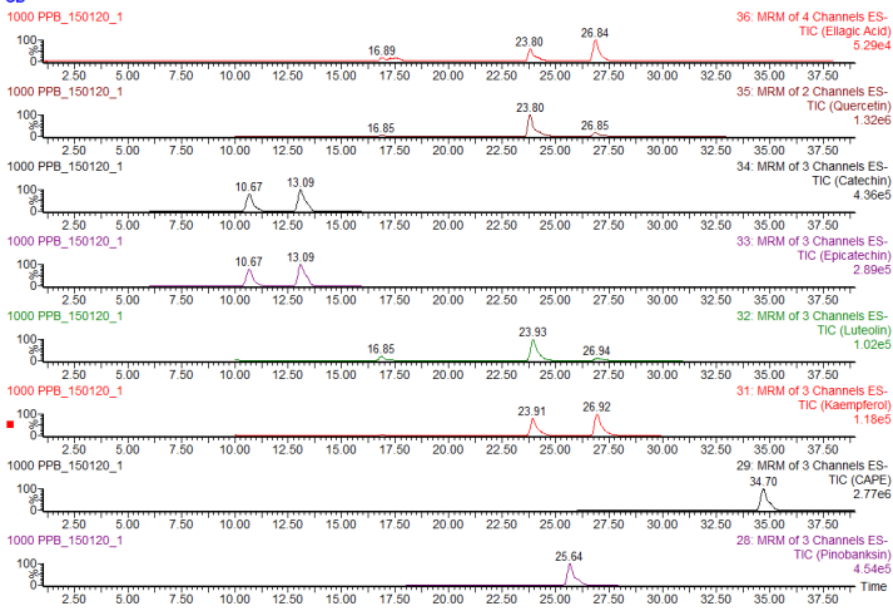

b)

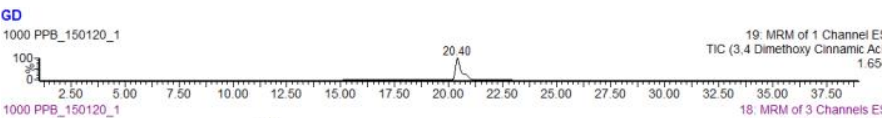
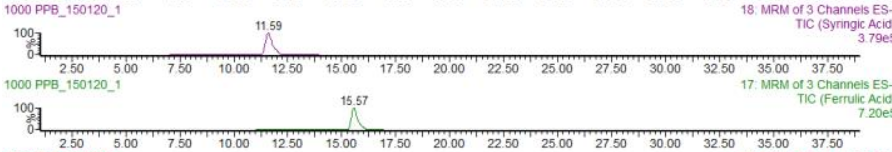

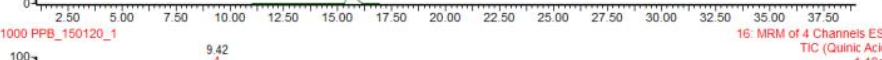

100
30
0

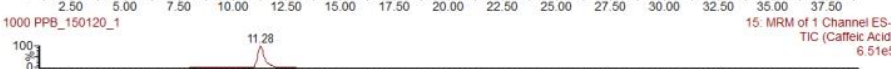

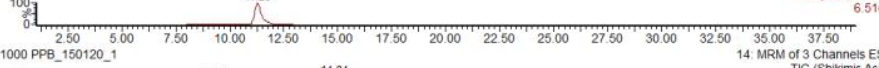

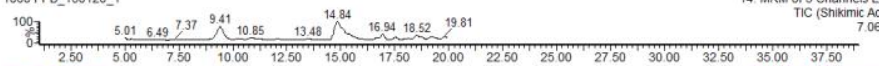

$1000 \mathrm{PPB}_{-} 500120 .-100$
4.04

${ }^{100} \mathrm{~T}_{0}$

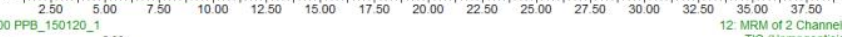

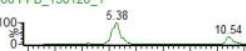

d)

e)

Şekil 1. Fenolik Bileşik Standartlarına Ait Kromatogramlar (Fig 1. Chromatograms of Phenolic Compound Standards)

a) Rutin Hydrate, Rosmarinic acid, Chlorogenic acid, Myricetin, Isorhamnetin, Gallo-Catechin, Epi-Gallo-Catechin, Hesperetin,

b) Ellagic acid, Quercetin, (+)-Catechin Hydrate, Epi-Catechin, Luteolin, Kaempferol, CAPE - Caffeic acid phenethyl ester, Pinobanksin,

c) Naringenin, Galangin, Genistein, Apigenin, Pinocembrin, Chrysin, Resveratrol, Methyl Syringate,

d) 3,4-Dimethoxy Cinnamic acid, Syringic acid, Quinic acid, Trans-Ferrulic acid, Caffeic acid, Shikimic acid, Gallic acid, Homogentisic acid,

e) Vanilic acid, Phenyllactic acid, m-Coumaric acid, o-Coumaric acid, p-Coumaric acid, Protocatechuic acid, 2-OH Cinnamic acid, 4-OH Benzoic acid 


\section{Araştırma Sonuçları ve Tartışma}

\subsection{Propolis Örneklerinin Toplam Fenolik ve Toplam Flavonoid Madde Miktarları}

Ürünlerin toplam fenolik (Şekil 2) ve toplam flavonoid madde (Şekil 3) miktarları Tablo 2'de gösterilmiştir.

Tablo 2. Propolis Örneklerinin Toplam Fenolik (mg GAE/L) ve Toplam Flavonoid (mg/L) Madde Miktarlarl (Table 2. Total Phenolic (mg GAE/L) and Flavonoid Content ( $\mathrm{mg} / \mathrm{L}$ ) of Propolis Samples)

\begin{tabular}{|c|c|c|}
\hline Ürün & $\begin{array}{c}\text { Toplam Fenolik Madde Miktarı } \\
(\mathbf{m g} \text { GAE/L) }\end{array}$ & $\begin{array}{c}\text { Toplam Flavonoid Madde Miktarı } \\
(\mathbf{m g} / \mathbf{L})^{*}\end{array}$ \\
\hline P1 & 2431 & 691 \\
\hline P2 & 2575 & 679 \\
\hline P3 & 116360 & 39437 \\
\hline P4 & 107339 & 5355 \\
\hline P5 & 32490 & 343 \\
\hline P6 & 4610 & - \\
\hline P7 & 33087 & 104 \\
\hline P8 & 20433 & 2327 \\
\hline P10 & 8900 & - \\
\hline P11 & 80467 & 20520 \\
\hline P12 & 83715 & 20740 \\
\hline P13 & 91550 & 21173 \\
\hline P14 & 124137 & 35292 \\
\hline
\end{tabular}

*Ürünlerin etiket üstünde beyan edilen propolis oranlarl farklı olduğu için toplam fenolik ve flavonoid madde miktarları her birinde \%50 propolis içermesi durumuna göre hesaplanmıştır.

-: tespit edilemedi.

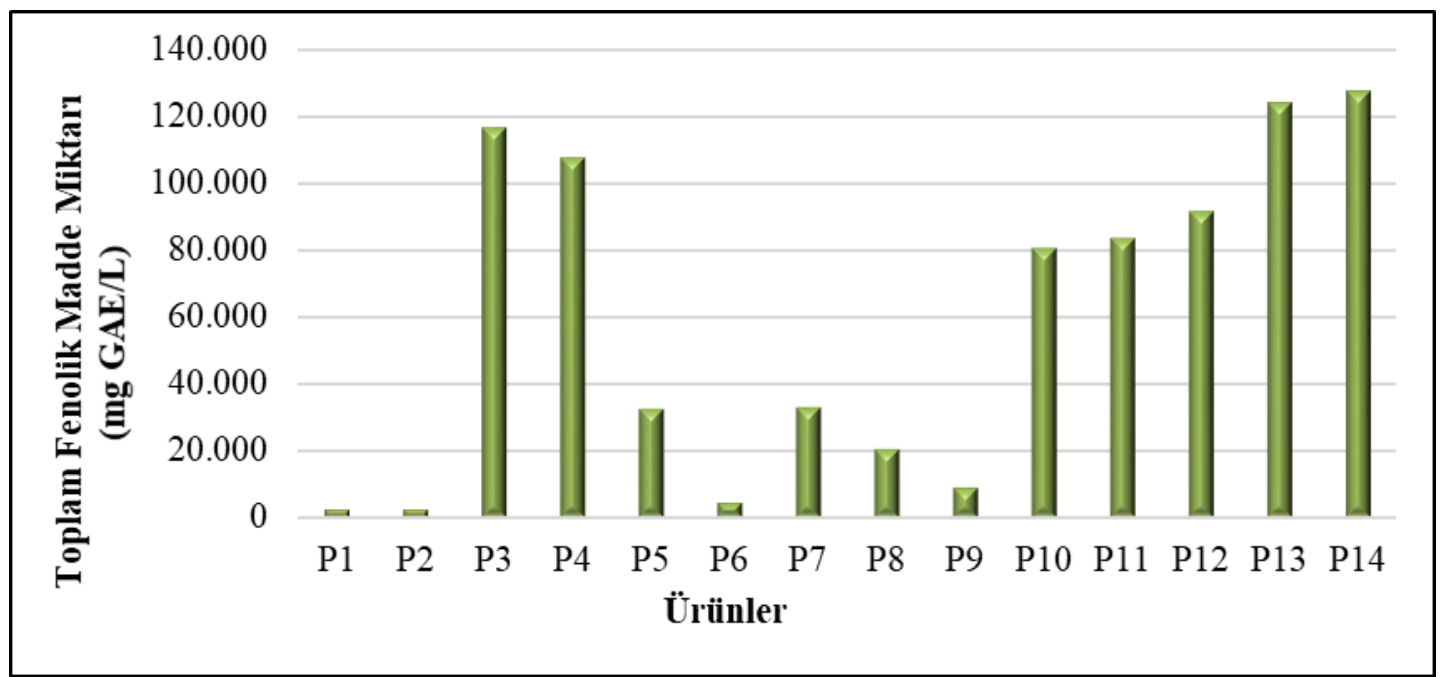

Şekil 2. Propolis Örneklerinin Toplam Fenolik Madde Miktarları (Fig 2. Total Phenolic Content of Propolis Samples)

Şekil 2'de görüldüğü üzere ticari propolis ürünlerinin toplam fenolik madde miktarları farklılık göstermektedir. En yüksek toplam fenolik madde içeriği; özel metot ile su kullanılarak ekstrakte edildiği beyan edilen P14 (127318 mg GAE/L) ve P13 (124137 mg GAE/L) 'de görülürken bunları sırasıyla suda çözünür P3 örneği (116360 mg GAE/L) ve etanolde ekstrakte edilmiş yeşil propolis olarak beyan edilen P4 (107339 mg GAE/L) ürünleri takip etmektedir. En düşük toplam fenolik madde içeriği ise su bazlı P1 (2431 mg GAE/L) ve P6 (4610 mg GAE/L) ürünleri ile su ve gliserol bazlı P2 (2575 mg GAE/L) ürünlerinde tespit edilmiştir. 


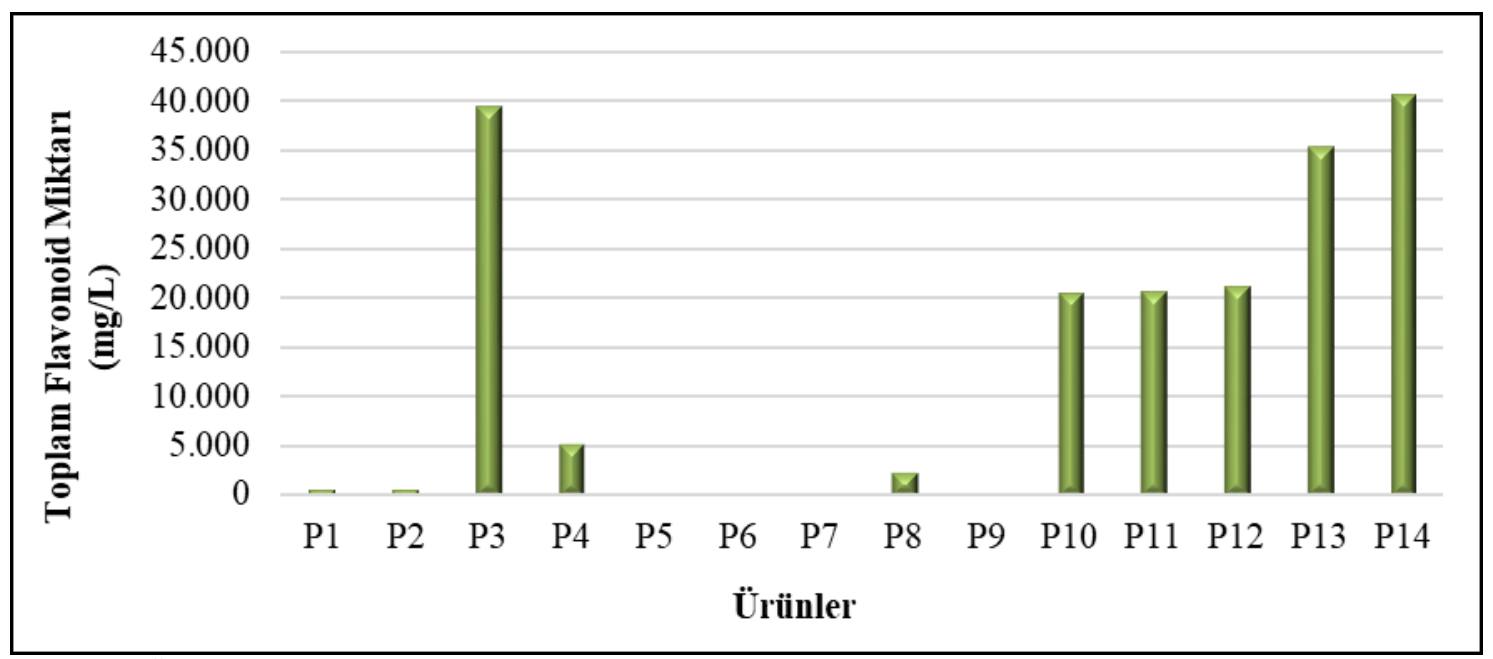

Şekil 3. Propolis Örneklerinin Toplam Flavonoid Madde Miktarları (Fig 3. Total Flavonoid Content of Propolis Samples)

Şekil 3'te ticari propolis ürünlerinin toplam flavonoid madde miktarları arasındaki farklılık görülebilmektedir. En yüksek toplam flavonoid madde miktarı; su bazlı tek kullanımlık saşe ürün olan P14'de (40516 mg/L) görülürken bunu sırasıyla su çözünür P3 örneği (39437 mg/L) ve su bazlı tek kullanımlık saşe ürün P13 (35292 mg/L) ürünleri takip etmektedir. Su bazlı P6 ve P9 ürünlerinde ise flavonoid madde belirlenememiştir.

\subsection{Propolis Örneklerinin Fenolik Bileşiklerinin Kompozisyonları}

Ürünlerin ayrıntılı fenolik kompozisyonları Tablo 3 ve Şekil 4’te gösterilmektedir. 
Tablo 3. Propolis Örneklerinin Fenolik Bileşiklerinin Kompozisyonu ( $\mathrm{mg} / \mathrm{L}) *$ (Table 3. Composition of Phenolic Compounds of Propolis Samples (mg / L) *) \begin{tabular}{|l|c|c|c|c|c|c|c|c|c|c|c|c|c|c|}
\hline Fenolik Bileşik & P1 & P2 & P3 & P4 & P5 & P6 & P7 & P8 & P9 & P10 & P11 & P12 & P13 & P14 \\
\hline
\end{tabular}

\begin{tabular}{|c|c|c|c|c|c|c|c|c|c|c|c|c|c|c|}
\hline \multicolumn{15}{|l|}{ Flavonoidler } \\
\hline Apigenin & 27 & 14 & 835 & 42 & - & - & - & 18 & - & 1023 & 944 & 737 & 976 & 1209 \\
\hline Chrisin & 317 & 220 & 10760 & 119 & 60 & - & 1 & 304 & - & 3007 & 2427 & 1610 & 8303 & 8516 \\
\hline Galangin & 130 & 243 & 11987 & 650 & 105 & - & 36 & 373 & - & 6420 & 8100 & 7902 & 9158 & 10038 \\
\hline Genistein & 5 & 1 & 598 & - & - & - & - & - & - & 507 & 593 & 656 & 78 & 1682 \\
\hline Hesperetin & 1 & 1 & 679 & - & - & - & - & - & - & 407 & 401 & 352 & 23 & 26 \\
\hline Isorhamnetin & - & - & 2221 & 70 & 5 & - & - & 15 & - & - & - & - & 92 & 145 \\
\hline Kaempferol & 4 & - & 215 & 1292 & 59 & - & 17 & 1 & - & 317 & 568 & 884 & 360 & 918 \\
\hline Luteolin & 4 & 5 & 874 & 62 & 30 & - & 5 & 22 & - & 193 & 652 & 732 & 372 & 360 \\
\hline Myristin & 12 & 12 & - & 42 & 2 & - & 28 & - & - & - & - & - & 295 & 153 \\
\hline Naringenin & - & 2 & 545 & 305 & - & - & - & 82 & - & 527 & 402 & 477 & 959 & 748 \\
\hline Pinobanksin & - & 33 & 927 & 244 & - & - & - & 723 & - & 2683 & 2075 & 1754 & 7708 & 8778 \\
\hline Pinocembrin & 181 & 136 & 5986 & 2170 & 12 & - & - & 705 & - & 4813 & 3921 & 3392 & 6651 & 7822 \\
\hline Quercetin & 4 & 4 & 1147 & 230 & 30 & - & - & 38 & - & 205 & 455 & 2105 & 131 & 48 \\
\hline Rutin & 4 & 8 & 2164 & 104 & 34 & - & 18 & 15 & - & 168 & - & 571 & 135 & 60 \\
\hline Taxifolin & 1 & 1 & 503 & 24 & 8 & - & - & 30 & - & 250 & 204 & - & 49 & 12 \\
\hline \multicolumn{15}{|l|}{ Fenolik asitler/Diğer } \\
\hline 2-OH Cinnamic Acid & 1 & 1 & - & 2 & - & - & 7 & - & - & - & - & - & 18 & 10 \\
\hline 3,4 Dimethoxy Benzaldehyde & 1 & 1 & - & 5 & - & - & - & - & - & - & - & - & 10 & 3 \\
\hline 3,4 Dimethoxy Cinnamic Acid & 62 & 73 & 4167 & 4 & 4 & - & 227 & 1250 & - & 2010 & 1619 & 1196 & 3566 & 4133 \\
\hline 4-OH Benzoic Acid & 28 & 9 & 401 & 260 & 85 & - & 65 & 93 & - & 253 & - & 81 & 134 & 150 \\
\hline Caffeic Acid & - & - & 326 & 1157 & 1868 & - & 1768 & 6474 & 1153 & 1877 & 1685 & 1158 & 4846 & 5589 \\
\hline Caffeic Acid Phenethyl Ester (CAPE) & 11 & 7 & 1474 & 217 & 40 & - & 17 & 328 & - & 2403 & 2357 & 1909 & 4526 & 5054 \\
\hline Catechin & 3 & 3 & - & 24 & 19 & - & 8 & 1 & - & - & - & - & 48 & 20 \\
\hline Chlorogenic Acid & - & - & - & 575 & 1139 & - & 1 & - & - & - & - & - & 46 & 17 \\
\hline Cinnamaldehyde & - & - & - & - & - & - & 15 & - & - & - & - & - & 94 & 22 \\
\hline Ellagic Acid & - & - & 503 & 50 & 38 & - & - & - & - & 220 & - & 160 & 127 & 125 \\
\hline Epicatechin & 3 & 3 & - & 25 & 19 & - & 10 & - & - & - & - & - & 33 & - \\
\hline Epigallocatechin & 5 & 5 & - & 55 & 102 & - & 9 & - & - & - & - & - & 75 & 18 \\
\hline Ferulic Acid & 3 & 3 & - & 207 & 91 & - & 163 & 388 & - & 343 & 489 & 883 & 1290 & 1561 \\
\hline Phenyllactic Acid & 17 & 16 & - & 19 & - & - & 4 & - & - & - & - & - & 96 & 72 \\
\hline Phloroglucinol & - & - & - & - & 51 & - & 49 & 24 & - & - & - & - & 36 & 1518 \\
\hline Gallic Acid & - & - & - & 2 & 5 & - & - & 2 & - & 92 & - & 30 & 1 & 5 \\
\hline Homogentisic Acid & - & - & - & 54 & 50 & - & 1 & - & - & - & - & - & 31 & 6 \\
\hline Protocatechuic Acid & - & 3 & - & 235 & 100 & - & 38 & 66 & - & 145 & - & 126 & 111 & 134 \\
\hline Quinic Acid & - & - & - & 660 & 1167 & - & 15 & - & - & - & - & - & 78 & 18 \\
\hline Resveratrol & - & - & - & 18 & 15 & - & 13 & - & - & 42 & - & 86 & 32 & 12 \\
\hline Rosmarinic Acid & 6 & 6 & - & 56 & - & - & - & - & - & - & - & - & 49 & 54 \\
\hline Shikimic Acid & - & - & - & 20 & - & - & - & - & - & - & - & - & - & 17 \\
\hline Syringic Acid & - & - & - & 30 & 23 & - & 5 & - & 47 & 40 & 359 & 474 & 35 & 8 \\
\hline m-Coumaric Acid & 1 & 1 & 2268 & 7 & 1 & - & 7 & - & - & 190 & 293 & 236 & 17 & 8 \\
\hline Methylshringat & - & - & - & 14 & 11 & - & 10 & - & - & - & - & - & 77 & 33 \\
\hline p-Coumaric Acid & 6 & 3 & 250 & 7315 & 1457 & - & 331 & 2058 & - & 327 & 502 & 617 & 1951 & 2247 \\
\hline Transcinnamic Acid & 46 & 37 & 1659 & 212 & 39 & 220 & 127 & 177 & - & 853 & 1.126 & 3532 & 1730 & 1831 \\
\hline Vanillic Acid & 27 & 8 & 433 & 24 & 20 & 5064 & 41 & . & 36 & 109 & - & 84 & 45 & 53 \\
\hline Toplam flavonoid madde miktarı (mg/L) & 691 & 679 & $\mathbf{3 9 4 3 7}$ & 5355 & 343 & - & 104 & 2327 & $\mathbf{0}$ & 20520 & 20740 & 21173 & 35292 & 40516 \\
\hline Toplam fenolik madde miktarı $(\mathrm{mg} / \mathrm{L})$ & 911 & 857 & 50916 & 16602 & 6685 & 5284 & $\mathbf{3 0 3 3}$ & 13188 & 1236 & 29423 & 29169 & 31743 & $\mathbf{5 4 3 9 5}$ & 63234 \\
\hline
\end{tabular}

Toplam fenolik madde miktarı (mg/L)

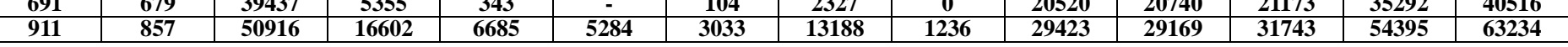

*Ürünlerin etiket üstünde beyan edilen propolis oranları farklı olduğu için toplam fenolik madde içerikleri her birinde \%50 propolis içermesi durumuna göre hesaplanmıştır.

-: tespit edilemedi. 


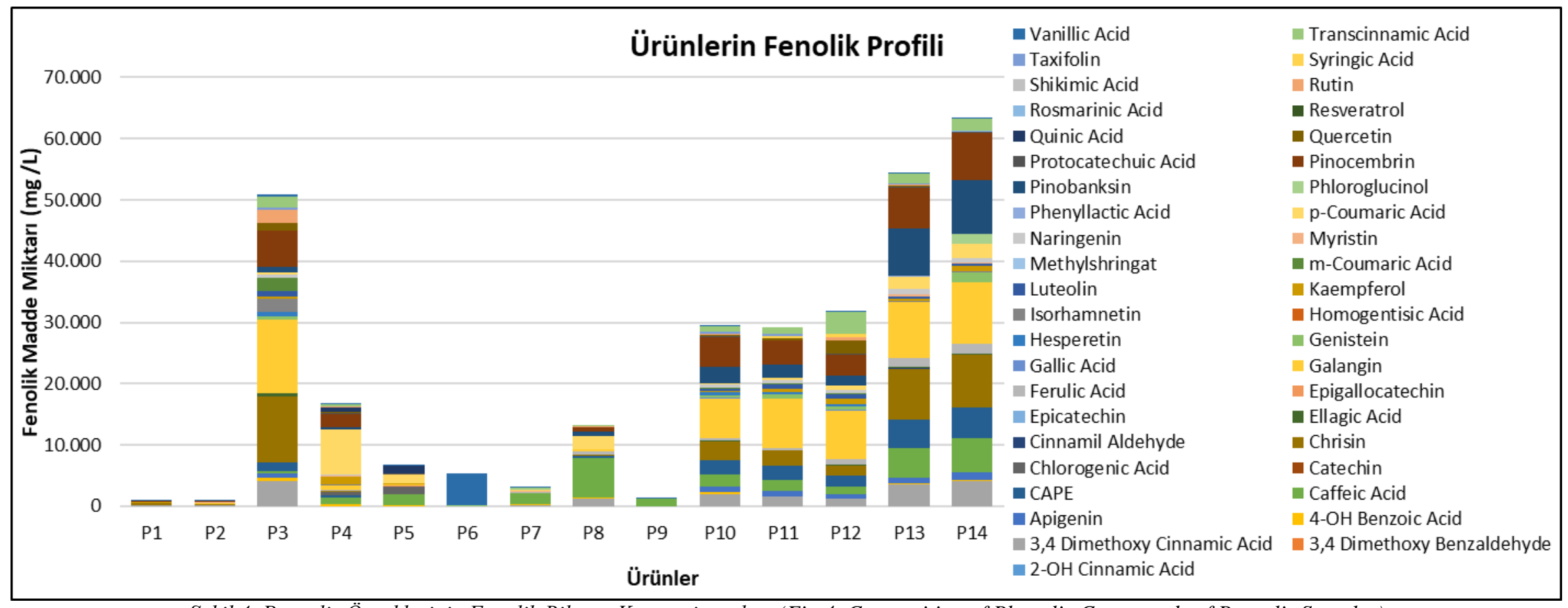

Şekil 4. Propolis Örneklerinin Fenolik Bileşen Kompozisyonları (Fig 4. Composition of Phenolic Compounds of Propolis Samples) 
Su bazlı damlalık şişe ambalajdaki propolis ürünü P1 örneğinin toplam fenolik madde miktarı $2431 \mathrm{mg}$ GAE/L ve toplam flavonoid miktarı $691 \mathrm{mg} / \mathrm{L}$ olarak saptanmıştır. Fenolik madde profiline bakıldığında en fazla chrisin flavonoidini içerdiği (317 mg/L) görülürken; isorhamnetin, naringenin, pinobanksin, caffeic acid, chlorogenic acid, cinnamaldehyde, ellagic acid, phloroglucinol, gallic acid, homogentisic acid, protocatechuic acid, quinic acid, resveratrol, shikimic acid, syringic acid ve methylshringat tespit edilememiştir.

Su bazlı damlalık şişe ambalajdaki propolis ürünü P2 örneğinin; toplam fenolik madde miktarı 2575 mg GAE/L ve toplam flavonoid miktarı $679 \mathrm{mg} / \mathrm{L}$ olarak saptanmıştır. Fenolik profiline bakıldığında en fazla galangin $(243 \mathrm{mg} / \mathrm{L}) \mathrm{ve} \mathrm{chrisin}(220 \mathrm{mg} / \mathrm{L}) \mathrm{içerdiği}$ görülmektedir. Öte yandan P1 örneğine benzer şekilde isorhamnetin, kaempferol, caffeic acid, chlorogenic acid, cinnamaldehyde, ellagic acid, phloroglucinol, gallic acid, homogentisic acid, quinic acid, resveratrol, shikimic acid, syringic acid, methylshringat tespit edilememiştir.

Yüksek fenolik madde içeriğine sahip ürünlerden biri olan alkolsüz suda çözünür damlalık şişe ambalajdaki P3 örneğinin analiz sonuçlarına bakıldığında; toplam fenolik madde miktarı $116360 \mathrm{mg}$ GAE/L, toplam flavonoid madde miktarı $39437 \mathrm{mg} / \mathrm{L}$ olarak saptanmıştır. Fenolik madde profili incelendiğinde; yüksek oranda galangin (11987 mg/L), chrisin (10760 mg/L), pinocembrin $(5986$ $\mathrm{mg} / \mathrm{L})$ içerdiği ve bunları 3,4 dimethoxy cinnamic acid $(4167 \mathrm{mg} / \mathrm{L}), \mathrm{m}$-coumaric acid $(2268 \mathrm{mg} / \mathrm{L})$, isorhamnetin $(2221 \mathrm{mg} / \mathrm{L})$, rutin (2164 mg/L), transcinnamic acid (1659 mg/L), CAPE (1474 mg/L) ve quercetin (1147 mg/L)'in izlediği görülmektedir. Myristin, 2$\mathrm{OH}$ cinnamic acid, 3,4 dimethoxy benzaldehyde, catechin, chlorogenic acid, cinnamaldehyde, epicatechin, epigallocatechin, ferulic acid, phenyllactic acid, phloroglucinol, gallic acid, homogentisic acid, protocatechuic acid, quinic acid, resveratrol, rosmarinic acid, shikimic acid, syringic acid, methylshringat belirlenememiştir.

Etanolde ekstrakte edilmiş yeşil propolis olarak beyan edilen damlalık şişe ambalajdaki P4 örneğinin; toplam fenolik madde miktarı $107339 \mathrm{mg}$ GAE/L, toplam flavonoid miktarı $5355 \mathrm{mg} / \mathrm{L}$ olarak belirlenmiştir. Fenolik madde profiline bakıldığında; p-coumaric acid (7315 mg/L), pinocembrin (2170 mg/L), kaempferol (1292 mg/L) ve caffeic acid (1157 mg/L) yüksek oranda içerdiği fenolik maddelerdir. Bununla birlikte genistein, hesperetin, cinnamaldehyde ve phloroglucinol tespit edilememiştir.

Su bazlı damlalık şişedeki propolis örneği P5'te; toplam fenolik madde miktarı $32490 \mathrm{mg}$ GAE/L, toplam flavonoid miktarı 343 mg/L olarak saptanmıştır. Yüksek oranda içerdiği fenolik maddeler; caffeic acid (1868 mg/L), p-coumaric acid (1457 mg/L), quinic acid (1167 mg/L) ve chlorogenic acid (1139 mg/L)'dir. Apigenin, genistein, hesperetin, naringenin, pinobanksin, 2-OH cinnamic acid, 3,4 dimethoxy benzaldehyde, cinnamaldehyde, phenyllactic acid, rosmarinic acid, shikimic acid ise belirlenememiştir.

Organik su bazlı propolis olarak beyan edilen damlalık şişe ambalajdaki P6 örneğinin analiz sonuçları; toplam fenolik madde miktarı $4610 \mathrm{mg}$ GAE/L olarak belirlenmiş, ancak flavonoid madde tespit edilememiştir. Üründe, analiz edilen fenolik maddeler arasından sadece vanillic acid (5064 mg/L) ve transcinnamic acid (220 mg/L) saptanmıştır.

Suda ekstrakte edildiği beyan edilen damlalık şişe ambalajdaki propolis örneği P7’de toplam fenolik madde miktarı 33087 mg GAE/L, toplam flavonoid miktarı $104 \mathrm{mg} / \mathrm{L}$ olarak belirlenmiştir. Yüksek oranda içerdiği fenolik madde ise; caffeic acid (1768 $\mathrm{mg} / \mathrm{L}$ )'dir. Apigenin, genistein, hesperetin, isorhamnetin, naringenin, pinobanksin, pinocembrin, quercetin ve taxifolin flavonoidleri ile 3,4 dimethoxy benzaldehyde, ellagic acid, gallic acid, rosmarinic acid, shikimic acid gibi fenolik maddeler tespit edilememiştir.

Su bazlı damlalık şişe içerisindeki P8 örneğinde; toplam fenolik madde miktarı $20433 \mathrm{mg}$ GAE/L, toplam flavonoid miktarı 2327 $\mathrm{mg} / \mathrm{L}$ olarak tespit edilmiştir. Caffeic acid (6474 mg/L), p-coumaric acid (2058 mg/L) ve 3,4 dimethoxy cinnamic acid (1250 mg/L) yüksek oranda içerdiği fenolik maddelerdir. Genistein, hesperetin, myristin, 2-OH cinnamic acid, 3,4 dimethoxy benzaldehyde, chlorogenic acid, cinnamaldehyde, ellagic acid, epicatechin, epigallocatechin, phenyllactic acid, homogentisic acid, quinic acid, resveratrol, rosmarinic acid, shikimic acid, syringic acid, m-coumaric acid, methylshringat ise tespit edilememiştir.

Organik su bazlı damlalık şişedeki P9 örneğinde toplam fenolik madde miktarı $8900 \mathrm{mg}$ GAE/L olarak belirlenmiştir. Toplam flavonoid miktarına bakıldığında ise; analiz edilen flavonoid maddelerden hiçbirinin saptanamadığı görülmektedir. Bu anlamda organik su bazlı P6 ürününe benzerlik göstermektedir. Tespit edilebilen fenolik maddeler caffeic acid (1153 mg/L), syringic acid (47 $\mathrm{mg} / \mathrm{L})$ ve vanillic acid (36 mg/L)'dir.

Su ve glikol ile ekstrakte edilidği beyan edilen damlalık şişedeki P10 örneğinde toplam fenolik madde miktarı 80467 mg GAE/L, toplam flavonoid miktarı $20520 \mathrm{mg} / \mathrm{L}$ olarak tespit edilmiştir. Yüksek miktarda içerdiği fenolik maddeler; galangin (6420 mg/L), pinocembrin (4813 mg/L), chrisin (3007 mg/L), pinobanksin (2683 mg/L), CAPE (2403 mg/L), 3,4 dimethoxy cinnamic acid (2010 $\mathrm{mg} / \mathrm{L})$, caffeic acid (1877 mg/L), apigenin (1023 mg/L)'dir. Öte yandan isorhamnetin, myristin, 2-OH cinnamic acid, 3,4 dimethoxy benzaldehyde, catechin, chlorogenic acid, cinnamaldehyde, epicatechin, epigallocatechin, phenyllactic acid, phloroglucinol, homogentisic acid, quinic acid, rosmarinic acid, shikimic acid ve methylshringat saptanmamıştır.

$\mathrm{Su}$ ve etanol ile ekstrakte edildiği beyan edilen damlalık şişedeki P11 örneğinde toplam fenolik madde miktarı 83715 mg GAE/L, toplam flavonoid miktarı $20740 \mathrm{mg} / \mathrm{L}$ olarak tespit edilmiştir. Yüksek oranda içerdiği fenolik maddeler; galangin (8100 mg/L), pinocembrin $(3921 \mathrm{mg} / \mathrm{L})$, CAPE $(2357 \mathrm{mg} / \mathrm{L})$, chrisin $(2427 \mathrm{mg} / \mathrm{L})$, pinobanksin $(2075 \mathrm{mg} / \mathrm{L}), \mathrm{caffeic}$ acid $(1685 \mathrm{mg} / \mathrm{L}), 3,4$ dimethoxy cinnamic acid (1619 mg/L), transcinnamic acid (1126 mg/L)'dır. Isorhamnetin, myristin, taxifolin, 2-OH cinnamic acid, 
3,4 dimethoxy benzaldehyde, 4-OH benzoic acid, catechin, chlorogenic acid, cinnamaldehyde, ellagic acid, epicatechin, epigallocatechin, phenyllactic acid, phloroglucinol, gallic acid, homogentisic acid, protocatechuic acid, quinic acid, resveratrol, rosmarinic acid, shikimic acid, methylshringat ve vanillic acid tespit edilememiştir.

Su ve etanol ile ekstrakte edildiği beyan edilen damlalık şişedeki P12 örneğinde toplam fenolik madde miktarı 91550 mg GAE/L, toplam flavonoid miktarı $21173 \mathrm{mg} / \mathrm{L}$ olarak belirlenmiştir. Galangin (7902 mg/L), transcinnamic acid (3532 mg/L), pinocembrin (3392 mg/L), quercetin (2105 mg/L), CAPE (1909 mg/L), pinobanksin (1754 mg/L), chrisin (1610 mg/L), 3,4 dimethoxy cinnamic acid $(1196 \mathrm{mg} / \mathrm{L})$, caffeic acid $(1158 \mathrm{mg} / \mathrm{L})$ yüksek oranda içerdiği fenolik maddelerdir. P11 örneğine benzer şekilde; isorhamnetin, myristin, taxifolin, 2-OH cinnamic acid, 3,4 dimethoxy benzaldehyde, catechin, chlorogenic acid, cinnamaldehyde, epicatechin, epigallocatechin, phenyllactic acid, phloroglucinol, homogentisic acid, quinic acid, rosmarinic acid, shikimic acid ve methylshringat tespit edilememiştir.

Özel metot ile su kullanılarak ekstrakte edildiği beyan edilen tek kullanımlık saşe ambalajdaki P13 örneğinin toplam fenolik madde miktarı 124137 mg GAE/L, toplam flavonoid miktarı 35292 mg/L olarak tespit edilmiştir. Yüksek oranda içerdiği fenolik maddeler; galangin $(9158 \mathrm{mg} / \mathrm{L})$, chrisin $(8303 \mathrm{mg} / \mathrm{L})$, pinobanksin $(7708 \mathrm{mg} / \mathrm{L})$, pinocembrin $(6651 \mathrm{mg} / \mathrm{L})$, caffeic acid $(4846 \mathrm{mg} / \mathrm{L}), \mathrm{CAPE}$ (4526 mg/L), 3,4 dimethoxy cinnamic acid $(3566 \mathrm{mg} / \mathrm{L})$, p-coumaric acid $(1951 \mathrm{mg} / \mathrm{L})$, transcinnamic acid $(1730 \mathrm{mg} / \mathrm{L}) \mathrm{ve}$ ferulic acid (1290 mg/L)'dir. Analiz edilen fenolik maddelerden sadece shikimic acid tespit edilememiştir.

Özel metot ile su kullanılarak ekstrakte edildiği beyan edilen tek kullanımlık saşe ambalajdaki P14 örneğinin toplam fenolik madde miktarı 127318 mg GAE/L, toplam flavonoid miktarı 40516 mg/L olarak tespit edilmiştir. P13 örneğine benzer şekilde yüksek oranda içerdiği fenolik maddeler; galangin $(10038 \mathrm{mg} / \mathrm{L})$, pinobanksin $(8778 \mathrm{mg} / \mathrm{L})$, chrisin $(8516 \mathrm{mg} / \mathrm{L})$, pinocembrin $(7822 \mathrm{mg} / \mathrm{L}), \mathrm{caffeic}$ acid $(5589 \mathrm{mg} / \mathrm{L})$, CAPE $(5054 \mathrm{mg} / \mathrm{L}), 3,4$ dimethoxy cinnamic acid (4133 mg/L), p-coumaric acid (2247 mg/L), transcinnamic acid (1831 mg/L), genistein (1682 mg/L), ferulic acid (1561 mg/L), phloroglucinol (1518 mg/L), apigenin (1209 mg/L)'dir. Analiz edilen fenolik maddelerden sadece epicatechin tespit edilememiştir.

Veriler genel olarak değerlendirildiğinde; en yüksek fenolik madde içeriğine sahip P14 ve P13 ürünlerinde fenolik madde çeşitliliğinin de fazla olduğu görülmektedir. P13 örneğinde shikimic acid dışındaki, P14 örneğinde pinobanksin, pinocembrin, caffeic acid, CAPE, ferulic acid, p-coumaric acid (Ristivojevic ve ark., 2015) ile 3,4 dimethoxy cinnamic acid ve transcinnamic acid gibi diğer fenolik maddeler her iki üründe de yüksek oranda tespit edilmiştir. Propolis ekstraksiyonunda en çok tercih edilen çözücü olan etanol bazlı P11 ve P12 örneklerinde ise birçok fenolik madde tespit edilememiştir. Bu durum kullanılan hammaddenin özelliğinden veya ekstraksiyon yönteminden kaynaklanabilir. P3, P10, P11 ve P12 örneklerinde, P13 ve P14 örneklerine benzer şekilde popolar propolisinin karakteristik bileşenleri (galangin, chrisin, pinobanksin, pinocembrin, caffeic acid, CAPE) nispeten yüksek oranda tespit edilmiştir. Su bazlı P6 ve P9 ürünlerinin ise fenolik madde çeşitliliği açısından çok fakir olduğu görülmektedir. P6 örneğinde sadece transcinnamic acid ve vanillic acid tespit edilirken, P9'da caffeic acid, syringic acid ve vanillic acid belirlenmiştir. Bununla birlikte ikisinde de flavonoid madde tespit edilememiştir. Sadece birkaç fenolik asit ekstrakte edilebilmesi ve flavonoid madde tespit edilememesi, kullanılan sulu ekstraksiyon yönteminin etkili olmamasından kaynaklanabilir. Toplam fenolik madde içeriği yüksek ürünlerden biri olan su bazlı P3 örneğinde ise çoğunlukla flavonoidler bulunurken birçok fenolik asitin ve flavanollerin bulunmadığı görülmektedir. Literatüre bakıldığında; flavonoidlerin genel olarak suda çözündüğü belirtilmektedir (Hazer ve ark., 2017). Öte yandan çözünebilir fenolik asitlerin genellikle metanol, aseton, su veya bunların belli oranlarda ve sıcaklıklardaki karışımlarından oluşan çözücüler ile bağlı fenolik asitlerin ise asit, alkali veya hem asit hem alkali hidrolizine tabi tutularak ekstrakte edilebildiği belirtilmektedir (Tuncel \& Yılmaz, 2010). Bu nedenle P3 örneğindeki bu durum kullanılan ekstraksiyon yöntemine bağlı olarak su ile bazı fenolik maddelerin ekstrakte edilemediğine bağlanabilir. Toplam fenolik madde içerikleri düşük olan su bazlı P1, P2, P5 ve P7 örneklerinde aynı şekilde flavonoid miktarlarının düşük ve fenolik madde çeşitliliğinin az olduğu görülmektedir. Bu durum hammadde ve ekstraksiyon metodu kaynaklı olabilir.

Yapılan bir çalışmada piyasadaki etanolik propolis ekstraktları temin edilerek flavonoid miktarları ve antimikrobiyal aktiviteleri saptanmıştır. 10 numunede yapılan çalışmada toplam flavonoid madde miktarı bizim çalışmamızdaki sonuçlara benzer şekilde farklılık göstermektedir. Ürün etiketlerinde beyan edilen propolis miktarları \%7 ile \%25 arasında değişmekle birlikte toplam flavonoid madde miktarlarına bakıldığında en düşük toplam flavonoid değeri \%0.78 (\%10 propolis içeren ürün); en yüksek toplam flavonoid değeri ise \%18.92 (\%25 propolis içeren ürün) şeklinde tespit edilmiştir (Kosalec ve ark., 2005). Başka bir çalışmada; 100 mL suda 10 g propolis ve $100 \mathrm{~mL} \% 70$ 'lik etanolde $10 \mathrm{~g}$ propolis 5 saat oda sıcaklığında çalkalanarak ekstrakte edilmiş ve toplam fenolik madde miktarları tespit edilmiştir. Su ile ekstraksiyon sonucu elde edilen numunede $1.6 \pm 0.4 \mathrm{mg} \mathrm{GAE} / \mathrm{ml}$; \% $\%$ 'lik etanol ile ekstraksiyon sonucu elde edilen numunede $12.7 \pm 1.2 \mathrm{mg}$ GAE/mL toplam fenolik madde saptanmıştır (Kubiliene ve ark., 2015). Sonuçlar \%50 propolis içermesi durumuna göre hesaplandığında suda ekstrakte edilen ürünün toplam fenolik madde miktarı (8000 mg GAE/L) su bazlı P9 örneğinin toplam fenolik madde miktarına (8900 mg GAE/L) yakın olduğu fakat su bazlı P3, P5, P7, P13 ve P14 örneklerinden oldukça düşük olduğu görülmektedir. Ayrıca su bazlı P6 ve P9 örnekleri dışında çalışmamızda incelenen tüm su bazlı propolislerde görülen galangin flavonoidi bu çalışmada su ile ekstrakte edilen numunede tespit edilememiştir. Yine \%50 propolis içermesi durumuna göre hesaplandığında; \%70'lik etanol ile ekstraksiyon sonucu elde edilen numunedeki toplam fenolik madde miktarının (63500 mg GAE/L) alkol bazlı P4, P11 ve P12 örneklerinden düşük olduğu görülmektedir. Bu durum kullanılan hammadde kaynaklı veya ekstraksiyon yöntemi ve koşulları ile ilgili olabilir. Diğer bir çalışmada farklı çözücülerde (su, etanol, propilen glikol) farklı oranlarda $(\% 2.5, \% 5$ ve $\% 10)$ propolisler kullanılarak farklı süre ve sicaklıklarda ekstrakte edilen propolislerin toplam fenolik madde miktarları belirlenmiştir. Sonuç olarak en yüksek toplam fenolik madde; \%10 propolis ile yapılan ekstraksiyonlarda elde edilmiştir. Çözücü olarak en etkilisinin etanol (171.4 $\pm 2.54 \mathrm{FAE} \mathrm{mg/g)} \mathrm{sonrasında} \mathrm{ise} \mathrm{propilen} \mathrm{glikol} \mathrm{(115.4 \pm 2.20} \mathrm{FAE} \mathrm{mg/g)} \mathrm{olduğu}$ 


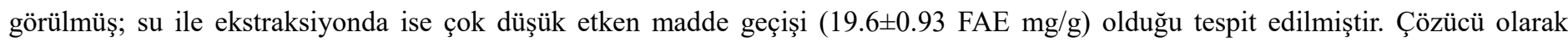
propilen glikol kullanılması durumunda karıştırma süresi ve sıcaklığının fenolik maddelerin ekstraksiyonunda etkili olduğu; optimum sıcaklığın $60^{\circ} \mathrm{C}$, sürenin ise 2 saat olduğu görülmüştür (Ramanauskien ve ark., 2013). Bu çalışmaya benzer başka bir çalışmada propolis numuneleri su, farklı oranlarda etanol:su $(\% 25, \% 50, \% 75, \% 90)$ çözeltileri ve etanol ile ultrasonik yöntemle ekstrakte edilmiş ve sonrasında numunelerde toplam fenolik ve toplam flavonoid madde miktarları tespit edilmiştir. Sonuçlara bakıldığında en

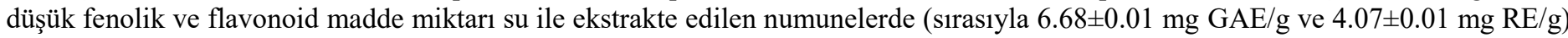
görülürken en yüksek fenolik ve flavonoid madde miktarı \%75 etanol:su çözeltisi ile ekstrakte edilen numunelerde (sırasıyla

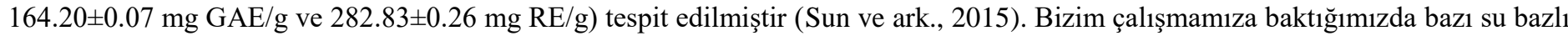
örneklerde çok düşük miktarda fenolik madde tespit edilirken bazılarında (P13 ve P14) ise alkol bazlı örneklerden daha yüksek oranda fenolik madde tespit edildiği görülmüştür.

\section{Sonuç}

Ticari propolis örnekleri incelendiğinde farklı oranlarda propolis içerdiği ve içeriklerinde alkol, su veya propilen glikol gibi alkol türevi maddelerin beyan edildiği görülmektedir. Ambalaj türü olarak damlalıklı şişe ve tek kullanımlık saşe kullanılmaktadır.

Piyasadan temin edilen örneklerde toplam fenolik ve toplam flavonoid madde miktarları ile fenolik bileşen kompozisyonları tespit edilmiştir. Elde edilen sonuçlar değerlendirildiğinde ticari propolis ürünlerinin biyoaktif madde miktarları ve çeşitliliği arasında farklılıklar olduğu açıkça görülmektedir. Daha önce yapılan çalışmalar incelendiğinde; konvansiyonel ekstraksiyon yöntemleri kullanılarak elde edilen su bazlı örneklerde biyoaktif madde içeriğinin alkol bazlı örneklere göre daha düşük olduğu görülmüştür. Bunun aksine, bizim çalışmamızda en yüksek toplam fenolik ve toplam flavonoid madde miktarı ile fenolik bileşen kompozisyonu özel metot ile su kullanılarak ekstrakte edilmiş tek kullanımlık saşe üründe tespit edilmiştir. Öte yandan su bazlı olarak beyan edilen bazı ürünlerde hem fenolik madde miktarının düşük hem de kompozisyonunun sınırlı olduğu görülmektedir. Tespit edilen bu farklılıkların kullanılan ekstraksiyon metodu ve hammaddenin niteliği ile ilgili olduğu düşünülmektedir.

Piyasadaki propolis örneklerinin içerdiği propolis oranı ve Helal gıda kapsamında çözücü madde türü tüketiciler için tercih sebebi olmaktadır. Fakat çalışma sonuçlarından da görüldüğü üzere propolis örneklerinde biyoaktif madde içeriği çözücüye göre kesin bir şekilde belirlenememektedir. Burada önemli olan kullanılan çözücüye uygun ekstraksiyon yönteminin ve kaliteli hammaddenin kullanılmasıdır. $\mathrm{Bu}$ anlamda, tüketicilerin satın alacakları ürünlerin içerdiği biyoaktif madde miktarı bilgisine ulaşabilmesi önem taşımaktadır.

\section{Kaynakça}

Ahangari, Z., Naseri, M., \& Vatandoost, F. (2018). Propolis: chemical composition and its applications in endodontics. Iranian Endodontic Journal, 13(3), 285-292.

Anjum, S.I.., Ullah, A., Khan, K.A., Attaullah, M., Khan, H., Ali, H., Bashir, M.A., Tahir, M., Ansari, M.J., Ghramh, H.A., Adgaba, N., \& Dash, C.K. (2018). Composition and functional properties of propolis (bee glue): a review. Saudi Journal of Biological Sciences, 26(7), 1695-1703.

Anonim. http://www.tab.org.tr/propolis Erişim tarihi: 13.04.2020

Arulanantham, K, \& Genel, M. (1978). Central nervous system toxicity associated with ingestion of propylene glycol. Journal of Pediatrics, 93(3), 515- 516.

Aybastıer, Ö. (2020). Farklı formlardaki ginkgo biloba'nın antioksidan özelliklerinin belirlenmesi. Avrupa Bilim ve Teknoloji Dergisi, $18,206-212$.

Bakkaloğlu, Z., \& Arıcı, M. (2019). Farklı çözücülerle propolis ekstraksiyonunun toplam fenolik içeriği, antioksidan kapasite ve antimikrobiyal aktivite üzerine etkileri. Akademik Glda, 17(4), 538-545.

Bayram, Y., Torlak, Y., \& Sağdıç, O. (2019). Üvez meyvesinin antioksidan aktivitesi. Avrupa Bilim ve Teknoloji Dergisi, 16, 933-939.

Belščak, A., Komes, D., Horžić, D., Ganić, K.K., \& Karlović, D. (2009). Comparative study of commercially available cocoa products in terms of their bioactive composition. Food Research International, 42, 707-716.

Bogdanov, S. (2017). Propolis: origin, production, composition. The Propolis Book, Chapter 1. Online: http://www.bee-hexagon.net Erişim Tarihi 12.04.2020.

Burdock, G.A. (1998). Review of the biological properties and toxicity of bee propolis (propolis). Food and Chemical Toxicology, 36(4), 347-363.

Cate, J.C., \& Hedrick, R. (1980). Propylene glycol intoxication and lactic acidosis. New England Journal of Medicine, $303,1237$.

Cornara, L., Biagi, M., Xiao, J., \& Burlando, B. (2017). Therapeutic properties of bioactive compounds from different honeybee products. Frontiers Pharmacology, 8, Article 412.

Devequi-Nunes, D., Machado, B.A., Barreto, G.D., Silva, J.R., Silva, D.F., Rocha, J.L., Brandão, H.N., Borges, V.M., \& Umsza-Guez, M.A. (2018). Chemical characterization and biological activity of six different extracts of propolis through conventional methods and supercritical extraction. PloS One, 13(12), e0207676.

Duman, S. (2010). Çanakkale (Türkiye) ilinde toplanan propolis örneklerinin antimikrobiyal aktiviteleri üzerine çalışmalar. Yüksek Lisans Tezi. Çanakkale Onsekiz Mart Üniversitesi, Fen Bilimleri Enstitüsü, Çanakkale.

Escriche, I., \& Juan-Borrás, M. (2018). Standardizing the analysis of phenolic profile in propolis. Food Research International, 106, 834-841. 
Farooqui, T., \& Farooqui, A. (2012). Beneficial effects of propolis on human health and neurological diseases. Frontiers in Bioscience (Elite edition), 4, 779-793.

Galeotti, F., Maccari, F., Fachini, A., \& Volpi, N. (2018). Chemical composition and antioxidant activity of propolis prepared in different forms and in different solvents useful for finished products. Foods, 7 (41), 1-10.

Glascow, A.M., Boeckx, R.L., Miller, M.K., MacDonald, M.G., August, G.P., \& Goodman, S.I. (1983). Hyperosmolality in small infants due to propylene glycol. Pediatrics, 72, 353-355.

Hazer, Y., Çölgeçen, H., \& Uyar, G. (2017). Briyofitlerden elde edilen fenolik bileşikler. Karaelmas Fen ve Mühendislik Dergisi, 7(1), 333-340.

Huang, S., Zhang, C., Wang, K., Li, G., \& Hu, F. (2014). Recent advances in the chemical composition of propolis. Molecules, 19, 19610-19632.

Kosalec, I., Pepeljnjak, S., Bakmaz, M., \& Vladimir-Knežević, S. (2005). Flavonoid analysis and antimicrobial activity of commercially available propolis products. Acta Pharm., 55(4), 423-430.

Kubilienè, L., Laugaliene, V., Pavilonis, A., Maruška, A., Majiene, D., Barcauskaite, K., Kubilius, R., Kasparavičienė, G., \& Savickas, A. (2015). Alternative preparation of propolis extracts: comparison of their composition and biological activities. BMC Complementary and Alternative Medicine, 15 (156), 1-7.

Lim, T.Y., Poole, R.L., \& Pageler, N.M. (2014). Propylene glycol toxicity in children. Journal of Pediatric Pharmacology and Therapeutics, 19(4), 277-282.

Martin, G., \& Finberg, L. (1970). Propylene glycol: a potentially toxic vehicle in liquid dosage form. Journal of Pediatrics, 77(5), 877-878.

O’Donnell, J., Mertl, S.L., \& Kelly, W.N. (2000). Propylene glycol toxicity in a pediatric patient: the dangers of diluents. Journal of Pharmacy Practice,13(3), 214-224.

Petkov, H.H., Trusheva, B., Popova, M., \& Bankova, V. (2018). Application of natural deep eutectic solvents for green extraction of bioactive compounds from poplar propolis: a preliminary study. Journal of Apitherapy and Nature/, 1(3), 76-76.

Popova, M.P., Bankova, V.S., Bogdanov, S., Tsvetkova, I., Naydenski, C., Marcazzan, G.L., \& Sabatini, A. (2011). Chemical characteristics of poplar type propolis of different geographic origin. Apidologie, 38, 306-311.

Ramanauskiene, K., Inkeniene, A., Petrikaite, V., \& Briedis, V. (2013). Total phenolic content and antimicrobial activity of different lithuanian propolis solutions. Evidence-Based Complementary and Alternative Medicine, Article ID 842985.

Ristivojevic, P., Trifkovic, J., Andrić, F., \& Milojković-Opsenica, D. (2015). Poplar-type propolis: Chemical composition, botanical origin and biological activity. Natural Product Communications, 10(11), 1869-1876.

Sun, C., Wu, Z., Wang, Z., \& Zhang, H. (2015). Effect of ethanol/water solvents on phenolic profiles and antioxidant properties of beijing propolis extracts. Evidence-Based Complementary and Alternative Medicine, Article ID 595393.

Toreti, V.C., Sato, H.H., Pastore, G.M., \& Park, Y.K. (2013). Recent progress of propolis for 1ts biological and chemical compositions and its botanical origin. Evidence-based Complementary and Alternative Medicine, 2013, 107-118.

Trusheva, B., Trunkova, D., \& Bankova, V. (2007). Different extraction methods of biologically active components from propolis: a preliminary study. Chemistry Central Journal, 1(13), 1-4.

Tuncel, N.B., \& Yılmaz, N. (2010). Kaz Dağları'ndan toplanan bazı bitkilerin fenolik asit kompozisyonlarının yüksek performanslı s1v1 kromatografisi ile belirlenmesi. Akademik Glda, 8(3), 18-23.

Uzel, A., Sorkun, K., Onçağ, O., Çoğulu, D., Gençay, O., \& Salih, B. (2005). Chemical compositions and antimicrobial activities of four different Anatolian propolis samples. Microbiological Research, 160(2), 189-95.

Zar, T., Graeber, C., \& Perazellat, M.A. (2007). Recognition, treatment and prevention of propylene glycol toxicity. Seminar in Dialysis, 20(3), 217-219. 